\title{
Isolation and screening of Bacillus subtilis MJ01 for MEOR application: biosurfactant characterization, production optimization and wetting effect on carbonate surfaces
}

\author{
Moein Jahanbani Veshareh ${ }^{1,4}$ C $\cdot$ Ehsan Ganji Azad ${ }^{2} \cdot$ Tahereh Deihimi $^{3} \cdot$ Ali Niazi $^{3} \cdot$ Shahab Ayatollahi $^{4}$
}

Received: 30 October 2017 / Accepted: 3 April 2018 / Published online: 11 April 2018

(c) The Author(s) 2018

\begin{abstract}
The bacterial strain MJ01 was isolated from stock tank water of one of the Iranian south oil field production facilities. The 16S rRNA gene of isolate, MJ01, showed 99\% similarity to Bacillus subtilis. The results revealed that biosurfactant produced by this strain was lipopeptide-like surfactin based on FTIR analysis. Critical micelle concentration of produced surfactin in distilled water was $0.06 \mathrm{~g} / \mathrm{l}$. Wettability study showed that at zero salinity surfactin can change original oil-wet state to water-wet state, but in seawater salinity it cannot modify the wettability significantly. To utilize this biosurfactant in ex situ MEOR process, economical and reservoir engineering technical parameters were considered to introduce a new optimization strategy using the response surface methodology. Comparing the result of this optimization strategy with the previous optimization research works was shown that significant save in use of nutrients is possible by using this medium. Furthermore, using this method leads to less formation damage due to the incompatibility of injecting fluid and formation brine, and less formation damage due to the bioplugging.
\end{abstract}

Keywords Microbial enhanced oil recovery $\cdot$ Surfactin $\cdot$ Wettability alteration $\cdot$ Box-Behnken design

\section{Introduction}

Oil recovery efficiency from oil reservoirs under natural driving mechanisms in most cases is relatively insufficient process and results in a low overall oil recovery. Continuous world energy demand while the energy sources are limited has coordinated researchers to work intensively on enhanced oil recovery (EOR) processes. Although different EOR methods have been developed, some of them were

Electronic supplementary material The online version of this article (https://doi.org/10.1007/s13202-018-0457-0) contains supplementary material, which is available to authorized users.

Moein Jahanbani Veshareh

Moein@dtu.dk

1 Centre for Oil and Gas, Danish Hydrocarbon Research and Technology Center, Denmark Technical University, 2800 Kongens Lyngby, Denmark

2 Iran National South Oil Company, Ahwaz, Iran

3 Institute of Biotechnology, Shiraz University, Shiraz, Iran

4 School of Chemical and Petroleum Engineering, Sharif University of Technology, Tehran, Iran appeared to be noneconomic or not environmental friendly (Al-Sulaimani et al. 2011). Microbial enhanced oil recovery (MEOR) in some reports has claimed to be cost-effective and less harmful to the environment (Krüger et al. 2016). MEOR is a biologically based technology, which mobilizes trapped oil by utilization of bioproducts through both in situ and ex situ processes. This technology has different mechanisms such as gas production, improving mobility ratio by oil viscosity reduction, biopolymer production, bioclogging, interfacial tension (IFT) reduction and wettability alteration (Armstrong and Wildenschild 2012a; Lazar et al. 2007; Sarafzadeh et al. 2013; Sivakumar et al. 2013; Soudmandasli et al. 2007; Zhao et al. 2017). However, the last two mechanisms have great importance, since IFT and wettability control capillary forces in porous media.

Biosurfactant plays an important role in most of the MEOR processes. In in situ MEOR, IFT reduction due to biosurfactant production and fluid diversion are the main mechanisms that take place when sugars are the carbon source (Nielsen 2010). In ex situ MEOR, biosurfactant is an effective EOR agent, while other mechanisms, such as bioclogging, are not beneficial (Armstrong and Wildenschild 2012b). Biosurfactants, as biodegradable materials, 
are suitable alternatives to replace toxic and low degradable chemical surfactants to reduce environmental risks (Reis et al. 2013). Sustainability is another superiority of biosurfactants to chemical surfactants, since biosurfactants can be produced from renewable feed stocks (Marchant and Banat 2012). Additionally, biosurfactants stability in harsh conditions of temperature, $\mathrm{pH}$ and salinity has made them preferable (Al-Wahaibi et al. 2014).

Despite all aforementioned advantages of biosurfactants, high feed and operational costs alongside to the low yield hinder the production of biosurfactants in industrial scales (Henkel et al. 2012). Several researches have been carried out to improve the economical production of biosurfactant, but most of them were not intended to use it in MEOR processes (Joshi et al. 2008b).

Brines of many sandstone and carbonate reservoirs are rich in $\mathrm{Ca}^{2+}$ (Austad 2013; Fisher and Boles 1990). These $\mathrm{Ca}^{2+}$ rich brines are not compatible with $\mathrm{H}_{2} \mathrm{PO}_{4}{ }^{-}$and $\mathrm{HPO}_{4}{ }^{2-}$ anions, which are present in most media used for biosurfactant production. It means that using these media at reservoir condition may lead to a significant formation damage. Moreover, in the previous research works, the optimum medium was considered as the medium in which the maximum biosurfactant yield is achieved. Therefore, previously reported values are not applicable for MEOR processes due to high nutrient loss and formation damage problem.

Considering the existing challenges and limitations associated with in situ MEOR, the aim of this article is to introduce new rules for designing an optimum ex situ MEOR process. After isolation, screening and identification of a biosurfactant-producing strain, surface activity and wettability study was done to ensure the capability of produced biosurfactant for improving oil recovery. Thereafter, it was tried to obtain an optimized and cost-effective production scheme for biosurfactant production. Box-Behnken experimental design was used to find the optimum point in the design space. The weight of extracted biosurfactant was considered as an index for biosurfactant production.

\section{Materials and methods}

\section{Isolation of oil degrading bacteria}

Soil contaminated with crude oil and stock tank water in sterile containers was collected from one of the Iranian south oil field production units. Two grams of the soil samples/two $\mathrm{ml}$ of water samples were enriched with $50 \mathrm{ml}$ of mineral salt base medium in 250-ml conical flasks. Medium was adopted from Peng et al. (2007), with the composition of Table S1; the medium was adjusted to $\mathrm{pH}$ 7.4. The trace element solution contained $\mathrm{ZnSO}_{4}, 0.29 ; \mathrm{CaCl}_{2}, 0.24 ; \mathrm{CuSO}_{4}$, $0.25 ; \mathrm{MnSO}_{4}, 0.17 \mathrm{~g} / \mathrm{l}$, and was sterilized separately. The enrichment process was conducted at $30{ }^{\circ} \mathrm{C}, 160 \mathrm{rpm}$ for 5 days.

Following the enrichment process, different dilutions of cultures up to $10^{8}$ were prepared and spread on Luria-Bertani (LB) agar medium composed of tryptone, 10; yeast extract, $5 ; \mathrm{NaCl}, 5$; agar, $15 \mathrm{~g} / \mathrm{l}$. After 1-3-day incubation at $30{ }^{\circ} \mathrm{C}$, morphologically different colonies were re-cultivated in fresh agar plates at least for three times to obtain pure cultures. Purity of isolates was confirmed through Gram staining (Gudiña et al. 2012).

All steps of the previous paragraph were repeated using another enrichment method to ensure enrichment method has not considerable effect on strains which are isolated. Bushnell Haas medium with the composition of Table S2 was adjusted to $\mathrm{pH}$ 7-7.2. Enrichment was conducted at $30{ }^{\circ} \mathrm{C}$ for 1 month (no shaking) (Bushnell and Haas 1941).

\section{Seed culture preparation}

LB broth medium was used for preparation of seed culture. Fifty milliliters of seed medium in 250-ml flask autoclaved and was inoculated with loop full of the pure microorganisms, which had been cultivated and grown on LB agar beforehand. Thereafter, inoculated flasks incubated for $24 \mathrm{~h}$ at $30^{\circ} \mathrm{C}, 160 \mathrm{rpm}$. Lastly, by using sterile seed medium the optical density at $600 \mathrm{~nm}$ was adjusted to 1 .

\section{Screening of biosurfactant-producing strains}

Mineral salt solution (MSSO) medium was used to study biosurfactant production. MSSO medium composed of $\mathrm{KH}_{2} \mathrm{PO}_{4}, 2.7 ; \mathrm{K}_{2} \mathrm{HPO}_{4}, 13.9 ; \mathrm{NaCl}, 1 ; \mathrm{NaNO}_{3}, 1$; yeast extract, 0.5; glucose and sun flower oil as two different carbon sources $10 \mathrm{~g} / \mathrm{l}$. This solution was supplemented with $10-\mathrm{ml}$ stock solution of $0.25 \%(\mathrm{w} / \mathrm{v}) \mathrm{MgSO}_{4}, 1 \%(\mathrm{w} / \mathrm{v})$ $\left(\mathrm{NH}_{4}\right)_{2} \mathrm{SO}_{4}$ and $10 \mathrm{ml}$ of trace element solution with the composition of Table S3, which were already filter sterilized separately (Darvishi et al. 2011). Flasks were inoculated with $1 \%(\mathrm{v} / \mathrm{v})$ of seed medium and incubated at $30^{\circ} \mathrm{C}$, $160 \mathrm{rpm}$ for $48 \mathrm{~h}$. After that for removing bacterial cells, samples were centrifuged at $9000 \mathrm{rpm}$ for $15 \mathrm{~min}$ and cellfree supernatants were used for oil spreading method to detect the biosurfactant-producing strains (Youssef et al. 2004). It should be noticed that sun flower oil as carbon source only was used in the screening step, and hereafter carbon source only refers to glucose.

\section{Identification of the bacteria}

Chromosomal DNA of screened bacteria was extracted using CinnaPure TM DNA extraction kit (Cinnagen, Iran) according to manufacturer's instructions. The 16S rRNA gene was amplified by PCR using universal primer: F: AGAGTTTGA 
TCCTGGCTCAG, R:ACGGCTACCTTGTTACGACTT (Weisburg et al. 1991). The reaction was performed in a total volume of $20 \mu \mathrm{l}$ and was set up as follows: $7 \mu \mathrm{l}$ of PCR master mix (Amplicon, Denmark), $1 \mu$ of each F and R primer, $1 \mathrm{ng}$ of template DNA and remaining volume $(10 \mu \mathrm{l})$ of sterile distilled water. The thermal condition was carried out in these steps: $94{ }^{\circ} \mathrm{C}$ for $5 \mathrm{~min}$ as initial denaturation, and 35 cycle at $94^{\circ} \mathrm{C}$ for $30 \mathrm{~s}, 57^{\circ} \mathrm{C}$ of annealing for 30 and $105 \mathrm{~s}$ for extension at $72{ }^{\circ} \mathrm{C}$, the PCR was terminated with 10 min at $72{ }^{\circ} \mathrm{C}$. The amplified product was detected on $1 \%$ gel electrophoresis, and the band similar to 1513 bp was cut and extracted by gel elution kit (GenMark Technology, Taichung, Taiwan). The extracted band then was sequenced by Macrogen Service Centre Advancing (Korea). The resulting sequence homology was compared to the GenBank database of the National Centre for Biotechnology Information (NCBI) using BLASTn algorithm. CLustalW was used for nucleotide sequence alignment. The neighbor joining tree construction was carried out using Molecular Evolutionary Genetics Analysis (MEGA) software version 6.0 (Lotfabad et al. 2009).

\section{Purification and partial identification of biosurfactant using FTIR}

Acid precipitation method was used for the extraction of biosurfactant. The cell-free supernatant (CFS) which was obtained by centrifuging culture at $9000 \mathrm{rpm}$ for $15 \mathrm{~min}$ was then used for biosurfactant extraction. The supernatant was subjected to acid precipitation by adding $6 \mathrm{M} \mathrm{HCl}$ to obtain $\mathrm{pH} 2$ and then kept at $4{ }^{\circ} \mathrm{C}$ overnight. Yellowish white precipitates were then collected by centrifugation at $9000 \mathrm{rpm}$ for $20 \mathrm{~min}$ and neutralized with alkaline water $(\mathrm{pH} 8, \mathrm{NaOH})$ and then lyophilized overnight (Pereira et al. 2013). To infer the overall nature of chemical bonds and structural groups in the extracted biosurfactant, Fourier transform infrared spectroscopy analysis was conducted with ABB Bomem MB 100. One hundred milligrams of $\mathrm{KBr}$ (Merck, Germany) and $1 \mathrm{mg}$ of extracted biosurfactant were completely mixed and pressed to obtain translucent pellets (Al-Wahaibi et al. 2014). FTIR spectral data with resolution of $2 \mathrm{~cm}^{-1}$ were collected between 400 and $4000 \mathrm{~cm}^{-1}$.

\section{Surface tension measurements}

For surface tension and IFT measurements, PAT-1 (SINTERFACE Technologies, Berlin) instrument was used. A detailed description of this instrument is reported in the work of Javadi et al. (2013), Loglio et al. (2001). Briefly, the setup is a dosing system with the accuracy of $\pm 0.02 \mu \mathrm{l}$ (which can be modified by changing the syringe size) connected to a capillary tube. The drop forms and grows with a respective liquid flow rate at the end of this capillary tube.
Two different cameras are utilized in the instrument, one with normal frame rate for direct surface tension measurements, and another with high frame speed (up to 3000 frame/s) for recording the drop shape and profile accurately. Finally, by fitting the Gauss-Laplace equation to the profile coordinates (extracted from drop images) surface tension values are obtained. Surface tension of each biosurfactant concentration was measured three times. Critical micelle concentration (CMC) is the surfactant concentration at and above which surfactant molecules form micelles instead of adsorbing on oil-water interface. Determination of CMC is one of the simplest ways to evaluate the usefulness of a surfactant. To determine this property, surface tension was plotted versus logarithm of biosurfactant concentration (Mukerjee and Mysels 1971). In order to investigate the stability of produced biosurfactant, surface tension of different seawater dilutions with the concentration of $0.6 \mathrm{~g} / \mathrm{l}$ biosurfactant was measured. Additionally, for taking into account the effect of salinity on surface tension, surface tension of different dilutions without biosurfactant was also measured. It should be noticed that the seawater that was used in this work had the total dissolved solid (TDS) content of 42,145 ppm.

For IFT measurements, CFS dilution of 1/20 (with distilled water) was prepared for each case in Table S5, and then IFT with n-heptane was measured for 3 times.

\section{Wettability studies}

\section{Oil}

Detail properties of the crude oil A used in this study have been reported in the work of Rashid et al. (2015).

\section{Rock slices}

Thin rock slices were prepared from carbonate outcrop, which was interpreted to be composed mainly from calcite based on X-ray diffraction (XRD) analysis (Fig. S1 in supplementary materials). Rock slices were polished with sandpapers of 100, 400 and 1000 grits, respectively, to ensure minimum surface roughness interferes in contact angle results (Le et al. 2011). Afterward for complete removal of any contamination, these slices were washed with water in an ultrasonic cleaner (Pars Nahand, PARSONIC $2600 \mathrm{~s}$, Iran) for $60 \mathrm{~min}$ with the frequency of $28 \mathrm{kHz}$ (Mahani et al. 2015).

\section{Contact angle tests}

In this study, contact angle test is used for wettability measurements. This method is the best method to evaluate influence of brine chemistry on wettability at experimental conditions. Between different methods of contact

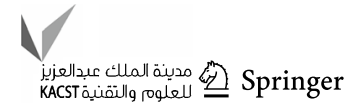


angle measurement, generally sessile drop method is used in petroleum engineering fields (Anderson 1986). The goal of contact angle measurements was to evaluate effect of the biosurfactant on calcite surfaces wettability. Figure S2 shows the setup by which the contact angles were measured at ambient temperature. This setup was composed of a syringe pump (JMS, SP-500, USA) with rate accuracy of $0.27 \mu \mathrm{l} / \mathrm{s}$, a digital microscope (Dino-Lite, Taiwan), a needle and an image processing software. In all contact angle tests, bulk and drop phase was not changed to ensure the change in contact angle is only due to the change in surface wettability; that is, liquid-liquid interfacial energy was kept constant so as to contact angle changes show changes in solid-liquid interfacial energy. Distilled water was used as bulk phase, and crude oil A was used as drop phase. Contact angles of slices were determined in following three steps:

1. After slices were washed, this contact angle shows the natural and initial wettability of calcite surfaces $\left(\theta_{\mathrm{i}}\right)$.

2. Washed slices were aged at $80{ }^{\circ} \mathrm{C}$ for 2 months in crude oil A to attain oil-wet state. Contact angles measured in this step illustrate wettability at reservoir condition $\left(\theta_{\mathrm{o}}\right)$.

3. In this step, the aged slices were transferred to four different following media for 2 weeks at laboratory temperature $\left(24-26^{\circ} \mathrm{C}\right)$. These media were $500 \mathrm{ppm}$ biosurfactant in distilled water, $500 \mathrm{ppm}$ biosurfactant in seawater, distilled water and seawater as control media. The contact angle results of this step were stored as the final wettability $\left(\theta_{\mathrm{f}}\right)$. For evaluation of biosurfactant ability to wettability reversal (wettability alteration toward water-wet state) of calcite surfaces, wettability reversal percent (WRP) with following definition was used.

$$
\mathrm{WRP}=\frac{\theta_{\mathrm{o}}-\theta_{\mathrm{f}}}{\theta_{\mathrm{o}}-\theta_{\mathrm{i}}} \times 100
$$

Value of WRP can vary between 0 and 100, which values close to 0 indicate no wettability change while values close to 100 indicate complete wettability reversal.

\section{Optimization of biosurfactant production}

\section{Biosurfactant production index (BPI)}

Biosurfactant was precipitated after adjusting the supernatant $\mathrm{pH}$ to 2.0 using $6 \mathrm{M} \mathrm{HCl}$ and was kept at $4{ }^{\circ} \mathrm{C}$ overnight. Following this, the biosurfactant precipitate was isolated by centrifugation at $9000 \mathrm{rpm}$ for $20 \mathrm{~min}$. The resulting precipitate then was dried in an oven for $24 \mathrm{~h}$ (until no change in weight was seen). Biosurfactant production index in $(\mathrm{g} / \mathrm{l})$ then calculated by the ratio of the biosurfactant dry weight to the initial sample volume (Nitschke and Pastore 2004).

\section{Biomass production index (MPI)}

For estimation of biomass produced in each culture medium, culture was centrifuged at $9000 \mathrm{rpm}$ for $15 \mathrm{~min}$. The cell precipitate was dried at $80{ }^{\circ} \mathrm{C}$ until a constant weight was attained (Tavassoli et al. 2012).

\section{Experimental design}

Response surface methodology (RSM) was used for investigating effects of four usual major nutrient, $\mathrm{H}_{2} \mathrm{PO}_{4}{ }^{-}, \mathrm{HPO}_{4}{ }^{2-}$, carbon source and yeast extract on bacterial growth and biosurfactant production (Abouseoud et al. 2008; Burgos-Díaz et al. 2011; Gudina et al. 2013; Illias et al. 1999; Najafi et al. 2015). In this study, $\mathrm{KH}_{2} \mathrm{PO}_{4}, \mathrm{~K}_{2} \mathrm{HPO}_{4}$ and glucose, respectively, were selected as $\mathrm{H}_{2} \mathrm{PO}_{4}^{-}, \mathrm{HPO}_{4}{ }^{2-}$ and carbon source. Yeast extract can be consumed by microorganisms as both carbon and nitrogen sources; however, herein it was considered as a general source, not a source for a special element. RSM is combination of empirical techniques that evaluates relation which exists between a cluster of controlled experimental parameters and the measured responses according to one or more selected criteria (Sen 1997). The objective is to find a desirable location in the design space. Box-Behnken designs are response surface designs, specially made to require only 3 levels, coded as $-1,0$, and +1 .

Box-Behnken design in accordance with Eq. (2) acquires data to fit a second-order polynomial model that includes both linear and interaction effects of variables.

$Y_{i}=\beta_{0}+\sum_{j=1}^{k} \beta_{j} x_{j}+\sum_{j=1}^{k} \beta_{j j} x_{j}^{2}+\sum \sum_{i<j}^{k} \beta_{i j} x_{i} x_{j}$

where $Y_{i}$ is predicted response, the coefficient $\beta_{0}$ is the offset or free term called intercept, $\beta_{j}$ is linear effect, $\beta_{j j}$ is squared effect, and $\beta_{i j}$ is interaction effect coefficient. Independent variables were coded in accordance with the following equation:

$x_{i}=\frac{\left(X_{i}-X\right)}{\Delta X_{i}}$

where $x_{i}$ and $X_{i}$ are the coded and actual value of the $i$ th independent value, $X$ is the actual value of the $i$ th variable at the central point, and $\Delta X_{i}$ is the step change in $X_{i}$ due to unit variation of the $x_{i}$. The "Design Expert" Software (version 7.0.0, Stat-Ease Inc., Minneapolis, USA) was used for design and analysis of experiments. Coded and actual values for the variables are given in Table S4. To estimate the pure error, sum of squares three replicates (runs 25-27) at the center of the design was used. Table S5 shows designed experiments. Twenty-seven experiments of Table S5 are 
27 culture media; concentration of effective components changes, while concentration of other components is constant equal to MSSO medium.

\section{Results and discussion}

\section{Isolation, screening and identification of biosurfactant-producing microorganisms}

To apply the ex situ MEOR process in the oil reservoir, for logistic and/or transportation issues the bioreactors should be placed near the target field. Bioreactors are controlled systems which their temperature can be set; however, this can impose some costs if the difference between the temperature of bioreactor and field is noticeable. For this reason, the compatibility of the candidate biosurfactant-producing bacteria with the oil field climate should be considered. In general, the regional indigenous microorganisms are compatible with the climate condition of that region. From both methods which were used for isolation fifteen different strains were obtained, which illustrates that proper isolation method has been used. Biosurfactant production ability of these different strains was evaluated through oil spreading method (data not shown). Among them, four strains were able to produce biosurfactant. However, MJ01 strain, which was grown in the medium with glucose as carbon source, showed the best biosurfactant production ability (more clear zone diameter). The analysis of $16 \mathrm{~S}$ rRNA partial sequence showed that the MJ01 strain is Bacillus subtilis by $99 \%$ similarity (Fig. 1). The 16S rRNA of this strain was submitted to GenBank with accession number KT188773.

\section{Partial identification of biosurfactant using FTIR}

Figure 2 shows IR spectra of biosurfactant produced by screened strain. Bands at $3392 \mathrm{~cm}^{-1}$ (NH stretch) and $1652 \mathrm{~cm}^{-1}$ (CO-N Stretch) are characteristic of peptides. The band at $1539 \mathrm{~cm}^{-1}$ is due to deformation mode of the $\mathrm{N}-\mathrm{H}$ bond in combination with the $\mathrm{C}-\mathrm{N}$ stretch (de Faria et al. 2011). The band at $1737 \mathrm{~cm}^{-1}$ is the characteristic of lactone carbonyl absorption (de Faria et al. 2011; Joshi et al. 2008a; Thaniyavarn et al. 2003). Bands at 2927 and $2957 \mathrm{~cm}^{-1}$ show asymmetric C-H stretch of methylene and methyl groups, respectively. Bands at 1456 and $1386 \mathrm{~cm}^{-1}$ show strong methylene/methyl bond and weak methyl bond, respectively (Coates 2000). Therefore, both aliphatic chains (hydrophobic domain) and peptide moiety (hydrophilic domain) exist in the produced biosurfactant. These pattern and bands are well similar to reports for lipopeptide biosurfactant surfactin (Al-Wahaibi et al. 2014).

\section{Surface activity of produced biosurfactant}

Figure 3 represents results of surface tension measurements for different concentration of biosurfactant produced by MJ01 strain. CMC value is the intersection point of two lines, which is $0.06 \mathrm{~g} / \mathrm{l}$. In the literature, different solutions with different
Fig. 1 Neighbor joining method, used for predicting phylogenetic tree by $16 \mathrm{~S}$ rRNA gene sequences, represents that the strain MJ01 belongs to Bacillus subtilis

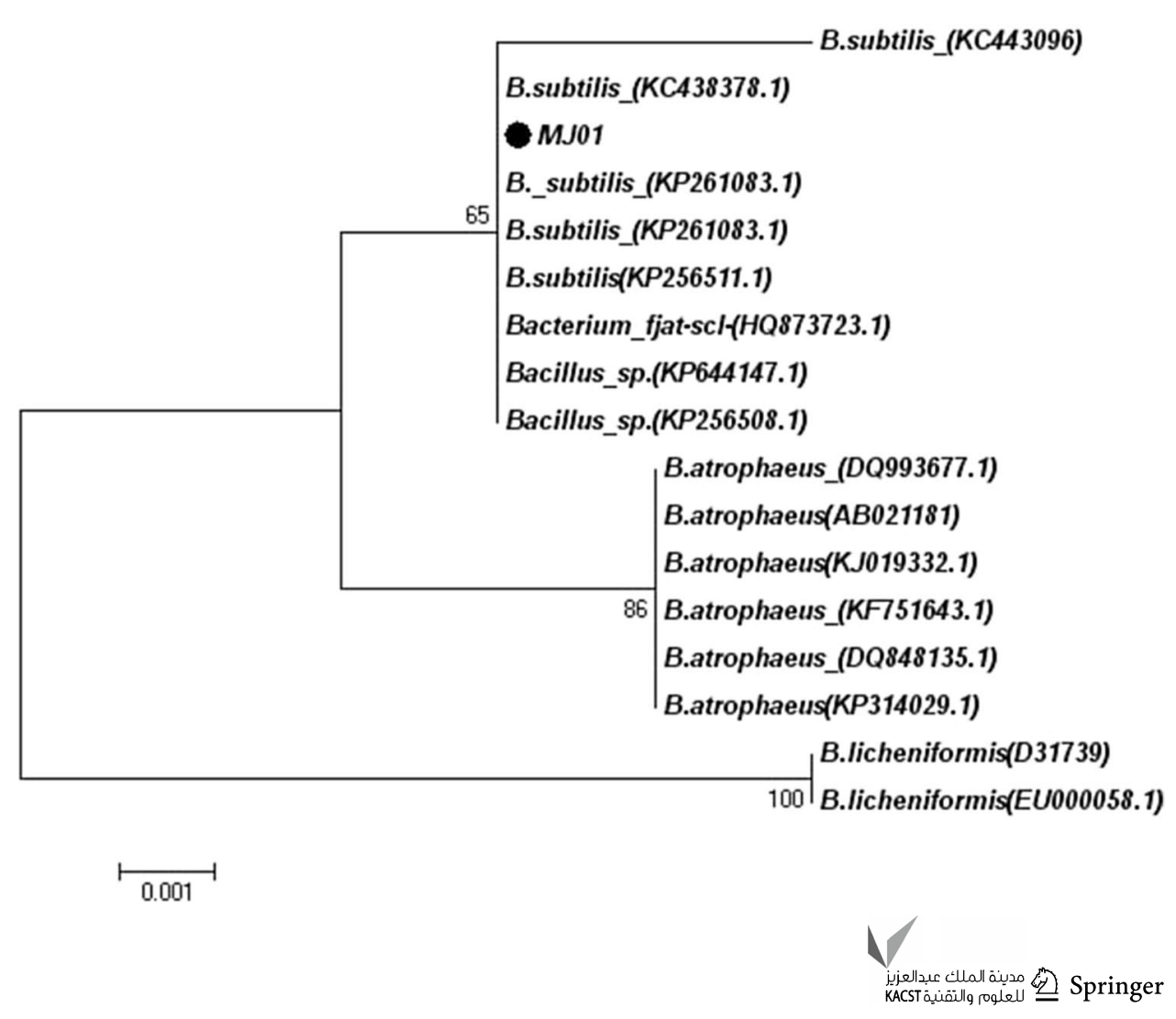


Fig. 2 FTIR spectra of biosurfactant produced by MJ01 isolate

Fig. 3 Surface tension versus concentration semilog plot for biosurfactant produced by MJ01 strain
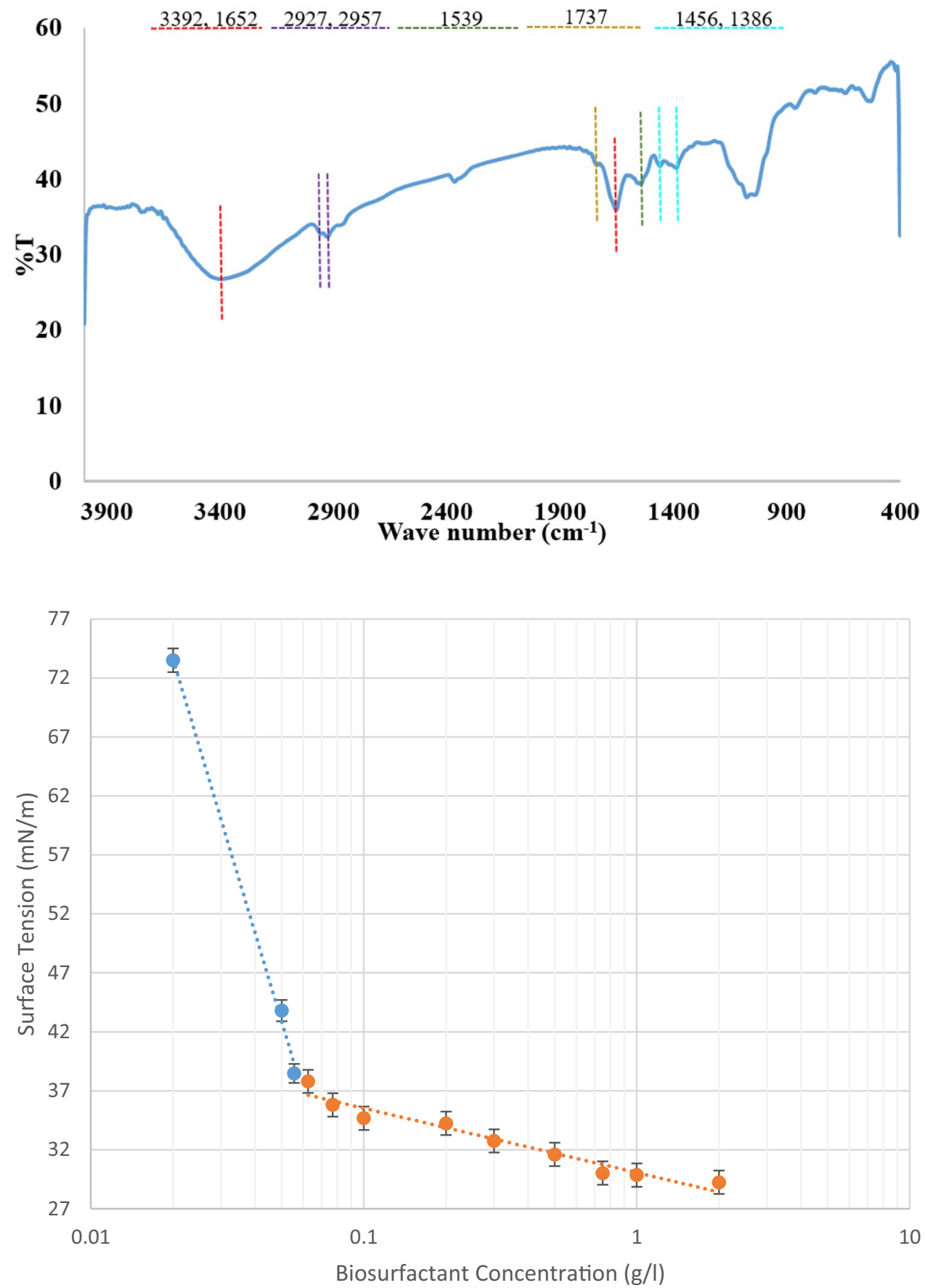

solvents were used for determination of CMC, which is illustrated in Table 1. Hence, to compare the surface activity of this biosurfactant with previously reported biosurfactants, the $\mathrm{CMC}$ values cannot be considered. So for doing valid comparison, the surface activity term can be defined as follows:

$\mathrm{SA}=\frac{\mathrm{ST}_{\mathrm{i}}-\mathrm{ST}_{\mathrm{f}}}{\mathrm{ST}_{\mathrm{i}} \times C_{\mathrm{bs}}}$ where $\mathrm{SA}$ is surface activity, $\mathrm{ST}_{\mathrm{i}}, \mathrm{ST}_{\mathrm{f}}$ are solution surface tensions before and after addition of biosurfactant, and $C_{\mathrm{bs}}$ is biosurfactant concentration at which $\mathrm{ST}_{\mathrm{f}}$ is measured, to compensate concentration effect on measured surface tensions. It is obvious that SA increases with increasing biosurfactant ability to reduce surface tension. As can be seen in Table 1, the SA of the surfactin produced by MJ01 is in good agreement with the work of Pereira et al. (2013) and greater than SA of other surfactin biosurfactants reported in the literature (de Faria et al. 2011; Pereira et al. 2013; 
Table 1 Surface activity (SA) of the surfactin produced by MJ01 strain in comparison with the literature

\begin{tabular}{|c|c|c|c|c|c|c|}
\hline References & $\mathrm{CMC}(\mathrm{g} / \mathrm{l})$ & Solvent & Concentration & $\mathrm{ST}_{\mathrm{i}}(\mathrm{mN} / \mathrm{m})$ & $\mathrm{ST}_{\mathrm{f}}(\mathrm{mN} / \mathrm{m})$ & SA \\
\hline Pereira et al. (2013) & 0.02 and 0.03 & $\begin{array}{c}10 \mathrm{mM} \mathrm{KH}_{2} \mathrm{PO}_{4} / \mathrm{K}_{2} \mathrm{HPO}_{4} \text { plus } \\
150 \mathrm{mM} \mathrm{NaCl}, \mathrm{pH} 7.0\end{array}$ & 1.002 & 68.2 & 27.9 & 0.59 \\
\hline Thimon et al. (1992) & $0.248(240 \mu \mathrm{mol} / \mathrm{l})$ & $5 \mathrm{mM}$ Tris unbuffered, $\mathrm{pH} 9.5$ & 0.48 & 58.74 & 34.28 & 0.87 \\
\hline de Faria et al. (2011) & $\sim 0.072(70 \mu \mathrm{mol} / \mathrm{l})$ & $\begin{array}{l}\text { Tris } \mathrm{HCl} \text { buffer, } \mathrm{pH} 8 \text {, for } \mathrm{CMC} \\
\text { Distilled water for } \mathrm{ST}\end{array}$ & 0.92 & 47.5 & 29.5 & 0.41 \\
\hline \multirow[t]{2}{*}{ This work } & 0.06 & Distilled water & 0.5 & 73.5 & 32.75 & 1.11 \\
\hline & & & 1 & & 29.85 & 0.59 \\
\hline
\end{tabular}

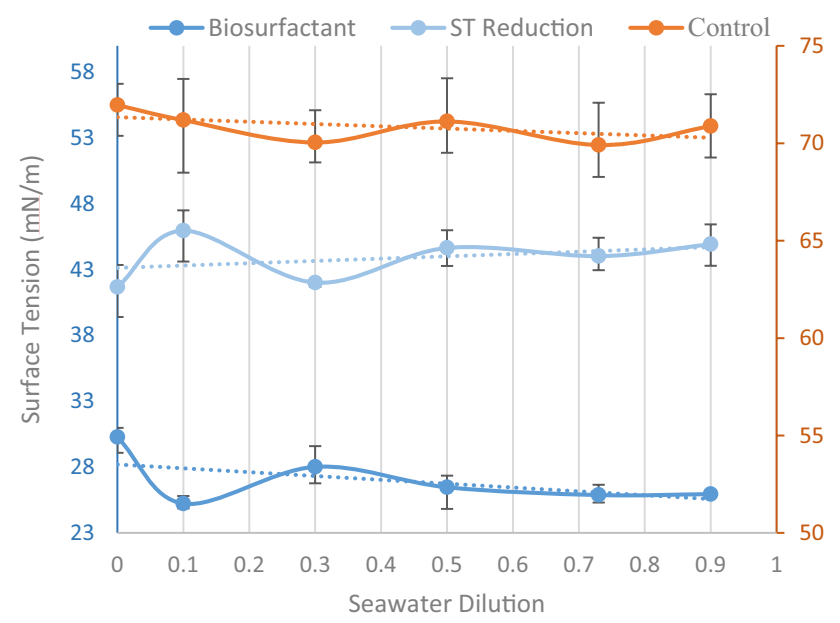

Fig. 4 Surface tension of different seawater dilutions with $0.6 \mathrm{~g} / \mathrm{l}$ biosurfactant

Thimon et al. 1992). Seawater is used as the injecting fluid in most of the water injection projects. Considering this fact, it is desirable if the biosurfactant can be injected with seawater instead of freshwater, without losing its effectiveness. Difference between surface tension of different seawater dilutions with and without biosurfactant was measured so as to elucidate stability of the biosurfactant in seawater. Figure 4 shows that increasing salinity up to $37,930 \mathrm{ppm}$ (seawater ratio of 0.9 ) cannot reduce surface activity of the biosurfactant. In this work, no stability analysis was done for higher salinities; however, Al-Bahry et al. (2013) showed that surfactin produced by a Bacillus subtilis strain is stable at higher salinities and temperatures up to $20 \mathrm{~g} / \mathrm{l} \mathrm{NaCl}$ and $100{ }^{\circ} \mathrm{C}$. Therefore, it is expected that the biosurfactant produced by MJ01 strain remains stable in reservoir condition.

To ensure the effectiveness of this biosurfactant on reducing capillary forces in porous media, IFT measurements were taken; Table S5 shows results of these measurements. As it can be seen 1/20 dilution of CFS of fourth run could reduce the IFT to $13.3 \mathrm{mN} / \mathrm{m}$. Therefore, this biosurfactant can increase oil recovery by reducing capillary forces in porous media. Although in this work oil recovery was not measured directly, Pereira et al. (2013) showed that biosurfactant produced by a Bacillus subtilis strain at a concentration of $1 \mathrm{~g} / \mathrm{l}$ can increase oil recovery by $19 \%$. Regarding the fact that biosurfactant produced by MJ01 has the same surface activity, it can be expected to observe similar oil recovery if one uses the biosurfactant produced by MJ01 strain at the same condition.

\section{Surfactin effect on calcite slices}

Wettability can be defined as the preference of one fluid to adsorb or spread on a solid surface in the presence of another immiscible fluid. In the case of fractured carbonate reservoirs, any alteration of wettability toward more waterwet state changes capillary forces direction so that spontaneous imbibition of water can occur. Therefore, in these reservoirs wettability alteration improves oil recovery. In the case of non-fractured carbonate reservoirs, Owens and Archer (1971) based on contact angle measurements showed that changing wettability from oil-wet to more neutral wet or water-wet state improves oil recovery significantly.

Extensive work has been done about effect of biosurfactants on the wettability. Al-Sulaimani et al. (2012) investigated effect of biosurfactant produced by a Bacillus subtilis strain on the strongly water-wet Berea sandstones; they observed wettability change toward less water-wet state. Karimi et al. (2012) evaluated effect of biosurfactant produced by Enterobacter cloacae on the wettability of aged glass slices. In this work, contact angle change from $\sim 110^{\circ}$ to $\sim 90^{\circ}$ was observed and it was concluded that biosurfactant has minor effect on the wettability. In the case of dolomite surfaces, Sarafzadeh et al. (2013) and Rabiei et al. (2013) from results of Amott tests showed that biosurfactant produced by Enterobacter cloacae changes wettability from strongly water-wet to neutral wet state. Despite these literatures, effect of biosurfactant on oil-wet calcite surfaces, which can be considered as a representative of carbonate reservoirs, was still an open question.

Table 2 shows the result of contact angle tests with WRP in different conditions. As can be seen surfactin effect in the salinity of seawater is less significant; however, even in

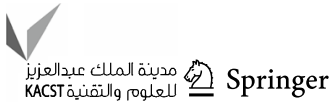


Table 2 Contact angle data of surfactin effect on calcite slices

\begin{tabular}{llrrrr}
\hline $\begin{array}{l}\text { Experiment } \\
\text { number }\end{array}$ & Description & \multicolumn{1}{l}{$\theta_{\mathrm{i}}$} & \multicolumn{1}{l}{$\theta_{\mathrm{o}}$} & \multicolumn{1}{l}{$\theta_{\mathrm{f}}$} & WRP (\%) \\
\hline 1 & Seawater (SW) & $33.4 \pm 1.6$ & $159.8 \pm 3$ & $151.6 \pm 6.8$ & 6 \\
2 & SW + 500 ppm biosurfactant & $29.9 \pm 3.4$ & $131.6 \pm 3.9$ & $118.5 \pm 2.2$ & 12 \\
3 & Distilled water & $45.5 \pm 4.4$ & $156 \pm 2.8$ & $141.1 \pm 0.6$ & 13 \\
4 & DW + 500 ppm biosurfactant & $42.6 \pm 3.8$ & $161.1 \pm 1.3$ & $45 \pm 4.9$ & 97 \\
\hline
\end{tabular}

the salinity of seawater the presence of biosurfactant led to $6 \%$ more WRP in comparison with the control case; that is, wettability has changed toward less oil-wet state. In the zero salinity, almost complete wettability reversal $(\mathrm{WRP}=97 \%)$ has occurred. Reason for this observation lies behind charge of the polar groups in surfactin. Due to the presence of two negative charges on the aspartate and glutamate residues of surfactin (Mulligan 2005), it can be considered as an anionic surfactant. Mechanism of wettability alteration by anionic surfactants is hydrophobic interaction of the surfactant tail with the crude oil components adsorbed in the rock surface. Formation of this so-called monolayer means that hydrophilic head groups of surfactants cover the oil-wet surface and change the wettability preference toward water-wet. In the zero salinity, only the hydrophobic-hydrophobic interactions between hydrophobic tail of surfactants and adsorbed crude oil components exist; however, in the salinity of seawater due to the presence of divalent cations such $\mathrm{Ca}^{2+}$ and $\mathrm{Mg}^{2+}$, hydrophilic (cation)-hydrophilic (anion) interactions exist too. These electrostatic interactions between divalent cations and negatively charged heads of surfactin molecules weaken hydrophobic interactions. Therefore, in the salinity of seawater, divalent cations keep some of the surfactin molecules in the bulk and reduce the ability of biosurfactant to change wettability. Connate water in carbonate reservoirs is usually rich in $\mathrm{Ca}^{2+}$ (Austad 2013); therefore, if biosurfactant is injected through freshwater, due to the mixing of injected fluid with formation brine, the wettability alteration is expected to be somehow less than the wettability alteration which was observed for the freshwater case. However, still a significant wettability change toward less oil-wet state or neutral wet state is expected to occur. If biosurfactant is injected through seawater, due to the mixing of injected fluid with formation brine, effect of biosurfactant is reduced to be even less than 6\% (based on WRP). Therefore, if this biosurfactant is injected through freshwater, wettability alteration has to be considered as a mechanism for improving oil recovery, whereas it can be ignored if the biosurfactant is injected through seawater.

\section{Optimization of biosurfactant production}

To determine the preliminary range of variables, two different, ideal and economical limits were considered. The ideal limit is the maximum feasible yield of biosurfactant, and the economical limit is the yield of biosurfactant by considering two important facts. The first evidence is that the extraction of biosurfactant from culture medium is not feasible both technically and economically; therefore, the raw biosurfactant in culture broth could be used directly for the injection process (Rabiei et al. 2013; Sarafzadeh et al. 2013; Souayeh et al. 2014). The second fact is the components of culture medium should be compatible with reservoir connate water to prevent formation damage. Connate water in carbonate reservoirs is usually rich in $\mathrm{Ca}^{2+}$ (Austad 2013), and also some sandstone reservoirs connate water is $\mathrm{Ca}^{2+}$ enriched (Fisher and Boles 1990). Two major components existing in almost all mineral salt base media are $\mathrm{H}_{2} \mathrm{PO}_{4}{ }^{-}$and $\mathrm{HPO}_{4}{ }^{2-}$ that precipitate and cause damage in the presence of $\mathrm{Ca}^{2+}$ (Dorozhkin 2009; Mooney and Meisenhelter 1960). Therefore, in this study the solubility of $\mathrm{Ca}\left(\mathrm{H}_{2} \mathrm{PO}_{4}\right)_{2}$ and $\mathrm{CaHPO}_{4}$ was evaluated for economical consideration. Table 2 presents the designed experimental parameters and their corresponding BPI. Equation (5) represents the best fitted second-order polynomial obtained through applying multiple regression analysis of the BPI results.

$$
\begin{aligned}
\mathrm{BPI}= & 0.86+0.21 \mathrm{~A}+0.081 \mathrm{~B}+0.09 \mathrm{C} \\
& -0.16 \mathrm{D}+0.22 \mathrm{AB}+0.13 \mathrm{BC} \\
& -0.18 \mathrm{~A}^{2}-0.19 \mathrm{~B}^{2}-0.14 \mathrm{C}^{2}-0.078 \mathrm{D}^{2}
\end{aligned}
$$

An ANOVA, Table S6, was performed to validate the regression coefficients.

Model terms with $P>F$ less than 0.05 are significant. Accordingly, all parameters except $D^{2}$ are significant. High $F$ value of model with low probability value (" $P_{\text {model }}>F$ " $<0.0001$ ) shows the significance of the model. Coefficient of determination, indicating how well the data fit a statistical model denoted by $R^{2}$, is large enough for this model $\left(R^{2}=0.9\right)$ and shows that only $10 \%$ of the total variations are not described by the model. High value of the adjusted determination coefficient (Adj $R^{2}=0.844$ ) confirms the significance of the model (Ahnazarova et al. 1982; Khuri and Cornell 1987). Besides, the relatively low value of coefficient of variation $(\mathrm{C} . \mathrm{V} \%=16.93)$ with high degree of precision indicates reliability of the experimental data (Box and Wilson 1951). 
In Fig. 5, 3D response surface shows the relationship between independent and dependent variables. Two variables change within their defined range, while two other variables are at fixed level. The maximum possible BPI (optimum $\mathrm{A}$ ) is $1.136 \mathrm{~g} / \mathrm{l}$ by using the following concentration for effective components: yeast extract $1.49 ; \mathrm{KH}_{2} \mathrm{PO}_{4} 7.62$; $\mathrm{K}_{2} \mathrm{HPO}_{4} 33.68$; glucose $11.9 \mathrm{~g} / \mathrm{l}$. There are several studies on the optimization of culture medium for surfactin production. Sen (1997) used $2^{4}$ full factorial central composite experimental design followed by multistage Monte-Carlo optimization to maximize the surfactin production. The optimum values corresponding to the maximum surfactin production, reported in terms of $\mathrm{CMC}^{-1}$ (critical micelle concentration), were 45.5. Jacques (1999) used Plackett-Burman designs to determine an optimum medium. In the reported optimum medium, peptone $(30 \mathrm{~g} / \mathrm{l})$ and yeast extract $(7 \mathrm{~g} / \mathrm{l})$ were used. Wei et al. (2007) achieved maximum surfactin yield of $3.34 \mathrm{~g} / \mathrm{l}$, where, $\mathrm{KH}_{2} \mathrm{PO}_{4}, \mathrm{Na}_{2} \mathrm{HPO}_{4}$ and glucose were used in concentrations of $30 \mathrm{mM}, 40 \mathrm{mM}$ and $40 \mathrm{~g} / \mathrm{l}$, respectively.
Joshi et al. (2008b) used $2^{4}$ full factorial central composite design to optimize the production of lichenysin. The medium in which maximum biosurfactant $(1.1 \mathrm{~g} / \mathrm{l})$ was produced was reported as optimum medium. This medium included $\mathrm{KH}_{2} \mathrm{PO}_{4}, 6 ; \mathrm{Na}_{2} \mathrm{HPO}_{4}, 2.7$; and glucose, $34 \mathrm{~g} / \mathrm{l}$. Roldán-Carrillo et al. (2011) conducted 15 experiments, designed by Box-Behnken method, to optimize biosurfactant production by Serratia marcescens bacteria, based on surface tension measurements. The reported optimum medium was included $\mathrm{K}_{2} \mathrm{HPO}_{4}, 4.4 ; \mathrm{KH}_{2} \mathrm{PO}_{4}, 3.4$; and glucose, $30 \mathrm{~g} / \mathrm{l}$. However, optimum concentration could be different with maximum possible BPI and should be obtained by considering the type of the process. These optimizations are fair only for fedbatch production of surfactin for biomedical applications not for MEOR processes.

From the petroleum engineering point of view, extraction of the biosurfactant in order to use in MEOR process would add extra cost while no significant excess oil recovery could be obtained (Rabiei et al. 2013; Sarafzadeh et al. 2013;
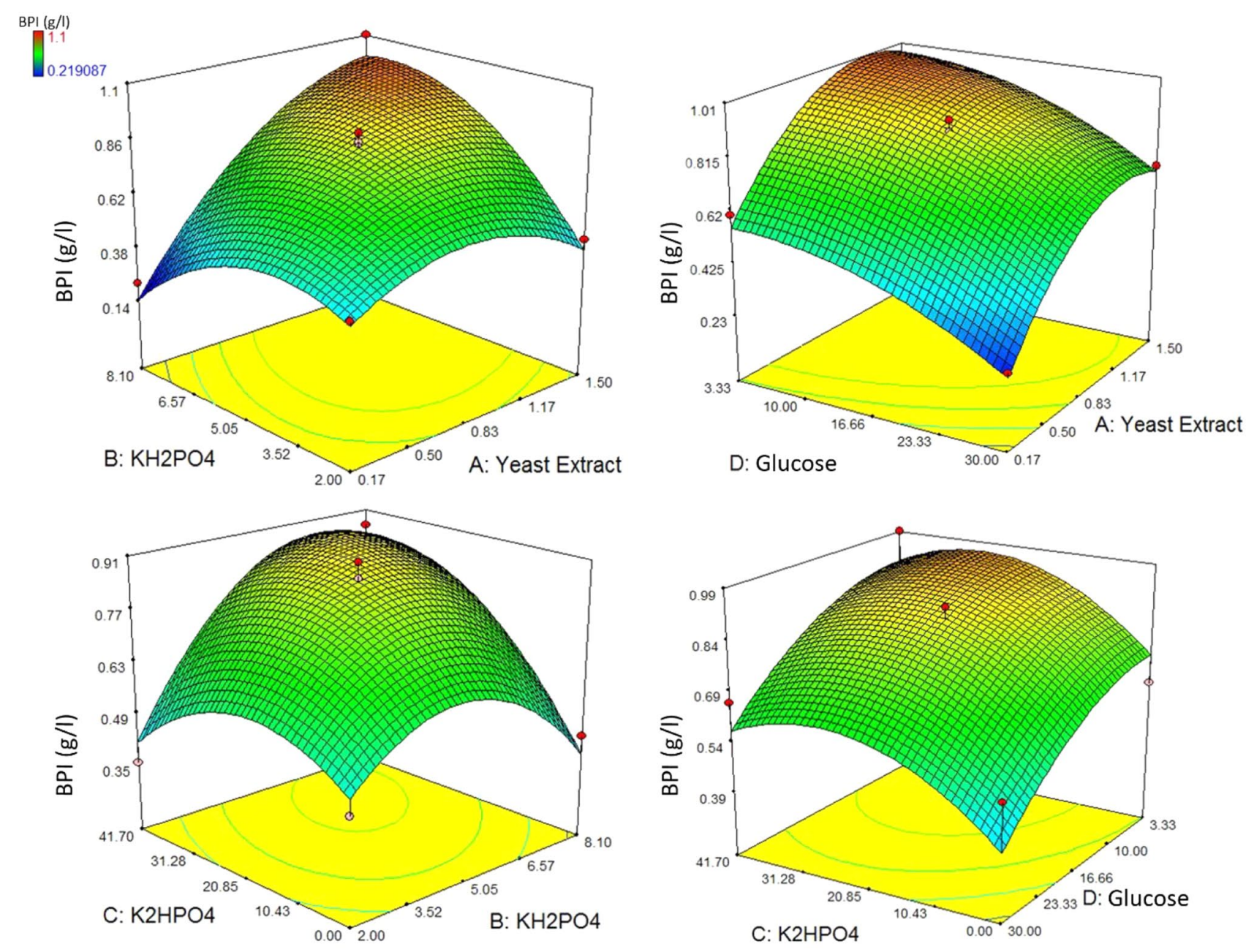

Fig. 5 RSM plot demonstrating effects of optimization variables; in each picture effect of two variables on BPI can be seen at fixed level of two other variables 
Souayeh et al. 2014). It means that instead of pure solution of biosurfactant, biosurfactant in the culture (without extraction) should be injected to reservoir without any recycling of nutrient components. Therefore, the optimum BPI production (optimum B) should be defined as the maximum BPI production at which residual concentration of nutrient components is minimum. It means that BPI productions more than this value is possible, but in expense of the more residual nutrient concentration. Furthermore, in the case of oil reservoirs which have $\mathrm{Ca}^{2+}$-rich connate water, if the optimum B definition is used, significant formation damage due to interaction between $\mathrm{Ca}^{2+}$ and phosphate ions would occur. In this case, optimum medium (optimum C) is a medium which is compatible with formation brine and produces maximum BPI with the lowest possible residual concentration of nutrient components. To determine optimum C, constrained optimization should be done regarding the compatibility of ions which are present in the medium and formation brine. To the best of the authors' knowledge in the previous biosurfactant optimization research works, which some of them were reviewed, only the optimum A definition has been used.

Considering optimum B definition, the optimum BPI was obtained to be $0.747 \mathrm{~g} / \mathrm{l}$ when the concentration of effective components was yeast extract $0.38 ; \mathrm{K}_{2} \mathrm{HPO}_{4} 24.23 ; \mathrm{KH}_{2} \mathrm{PO}_{4}$ 3.44; and glucose $3.33(\mathrm{~g} / \mathrm{l})$. In order to illuminate the importance of optimum B definition, BPI productions based on optimum A and B definitions, and their corresponding culture media should be compared. The ratio of biosurfactant yield which is obtained by optimum A to optimum $\mathrm{B}$ is 1.521 , while the ratio of needed nutrients is $3.92,1.39$, 2.21 and 3.57 for yeast extract, $\mathrm{K}_{2} \mathrm{HPO}_{4}, \mathrm{KH}_{2} \mathrm{PO}_{4}$ and glucose, respectively. It is clear that nutrient ratios which are more than 1.521 are wastes which occur if optimum $\mathrm{A}$ is used instead of optimum B. As an another example, in order to show the importance of this optimization procedure, optimum B value of this work was compared with the suggested surfactin optimum value of Wei et al. (2007). The ratio of biosurfactant yield of optimum B to the biosurfactant yield reported by Wei et al. (2007) is 0.224 , while ratio of glucose which is used is 0.0825 . It means that 12 -fold glucose consumption produces only 4.471-fold biosurfactant; that is, significant waste of nutrition occurs if Wei et al. (2007) culture media are used instead of optimum B.

Figure 6 shows optimum $\mathrm{C}$ medium, which is designed to be applicable in oil reservoirs with connate water rich in $\mathrm{Ca}^{2+}$. The maximum BPI in this case was $0.571 \mathrm{~g} / 1$ when concentration of effective components was yeast extract, 0.809; glucose, 3.33; $\mathrm{KH}_{2} \mathrm{PO}_{4}, 2$; and $\mathrm{K}_{2} \mathrm{HPO}_{4}, 0 \mathrm{~g} / \mathrm{l}$.

\section{Biomass production}

In the previous sections, considering technical constraints of MEOR process different optimum media were defined. These media were compared from economical point of view, and formation damage can be occurred due to incompatibility
Fig. 6 Possible obtainable BPI in the media compatible with carbonate reservoir brine

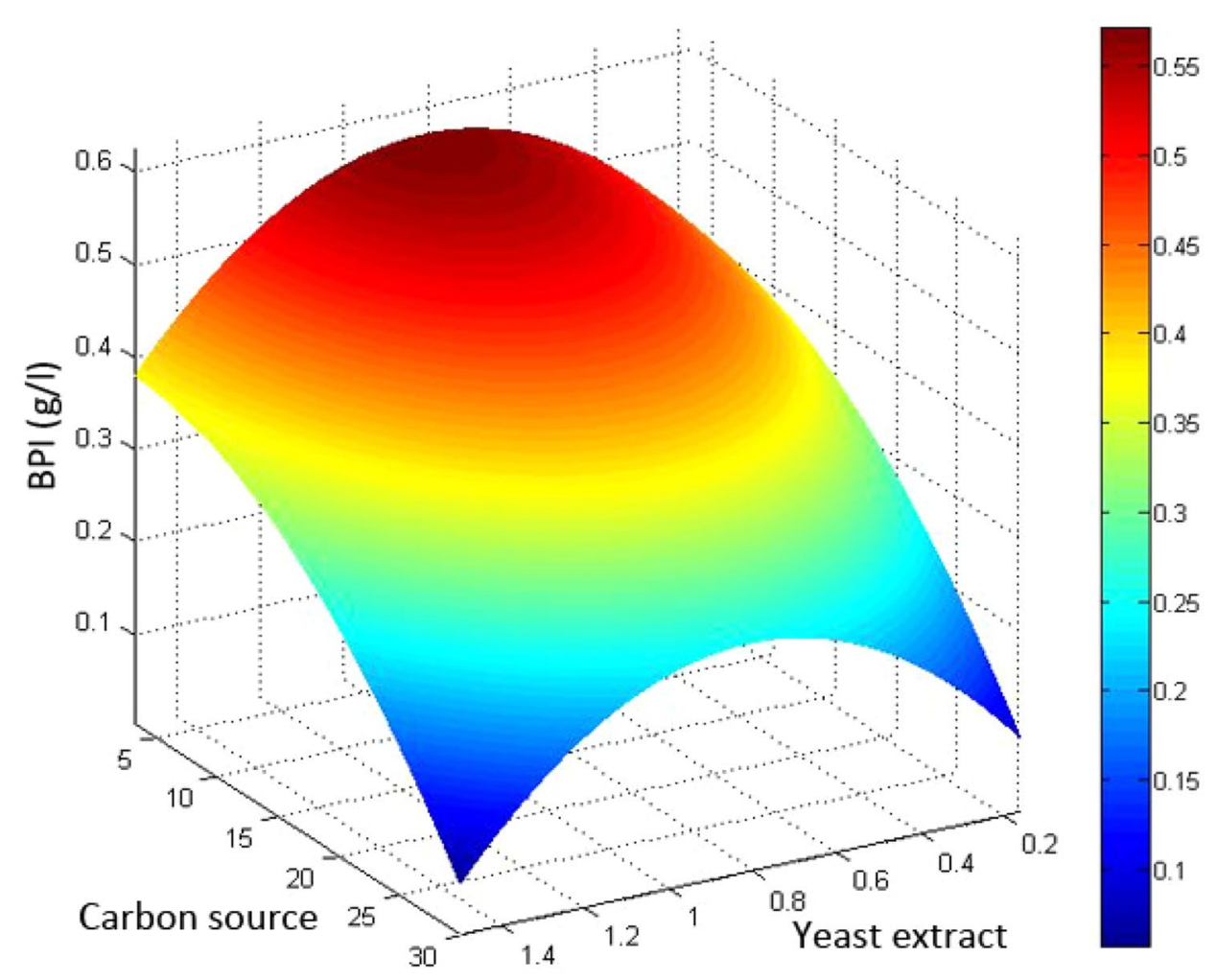


of culture media and formation brine. However, there is still another aspect based on which these media can be compared. Considering the biomass production, plugging of the porous rock, and consequently reduction in permeability can occur during MEOR processes. This biomass affected plugging is dependent on bacteria biomass/cell concentration of injecting fluid (Shaw et al. 1985). Assuming the injection of CFS, the culture media which produce more biomass introduce more biomass isolation cost. Assuming the injection of culture including the biomass, the culture media which produce more biomass introduce more biomass affected formation damage. Therefore, the culture media which produce less biomass are more favorable. Biomass production in each experiment was measured in order that it can be possible to compare different media based on biomass production. A second-order polynomial model was developed for estimation of biomass production; Eq. (6) represents the code form of this model:

$$
\begin{aligned}
\text { MPI }= & 2.28+0.088 \mathrm{~A}+0.041 \mathrm{~B}+0.23 \mathrm{C}-1.13 \mathrm{D} \\
& -0.42 \mathrm{~A}^{2}-0.37 \mathrm{D}^{2}
\end{aligned}
$$

$P>F, F$ value, $R^{2}$, Adj $R^{2}$, C.V. $\%$ and adequacy precision for this model was $<0.0001,26.15,0.8836,0.8478,17.65$ and 17.202, which show the significance and adequacy of the model.

In this case, biomass production corresponding to optimum A, B and C was $1.684,0.543$ and $0.505 \mathrm{~g} / \mathrm{l}$, respectively. It means that for producing 1.521 -fold biosurfactant, optimum A produces almost threefold biomass in comparison with optimum B and C. These data illustrate that in addition to economical and compatibility preference of optimum $\mathrm{B}$ and $\mathrm{C}$, they are more favorable from biomass production point of view as they produce less biomass and they lead to less degree of bioplugging.

\section{Conclusions}

This study showed:

- In ex situ MEOR processes by Bacillus subtilis strain in carbonate reservoirs, wettability changes to less oilwet state. Therefore, in this process wettability alteration should be considered as an oil recovery mechanism beside the IFT reduction.

- Based on definition of surface activity term, surfactin produced by MJ01 has strong surface activity which proves its potential to use as an EOR agent.

- The nutrients used in medium preparation are not recycled during the MEOR process; hence, the cost involved would affect the selection of optimized condition. The economical assessment in this study showed that biosur- factant optimization for MEOR process should specify the culture media which leads to maximum biosurfactant production alongside with the minimum residual nutrient concentration, or minimum nutrient waste.

- The formation damage is another important aspect which should be considered for any MEOR process optimization. Constraint optimization should be done in order to avoid formation damage problem during the MEOR process.

Open Access This article is distributed under the terms of the Creative Commons Attribution 4.0 International License (http://creativeco mmons.org/licenses/by/4.0/), which permits unrestricted use, distribution, and reproduction in any medium, provided you give appropriate credit to the original author(s) and the source, provide a link to the Creative Commons license, and indicate if changes were made.

\section{References}

Abouseoud M, Maachi R, Amrane A, Boudergua S, Nabi A (2008) Evaluation of different carbon and nitrogen sources in production of biosurfactant by Pseudomonas fluorescens. Desalination 223(1):143-151

Ahnazarova SL, Kafarov VV, Mackovskij VM, Rep'ev AP (1982) Experiment optimization in chemistry and chemical engineering. Mir Publishers, Moscow

Al-Bahry S et al (2013) Biosurfactant production by Bacillus subtilis B20 using date molasses and its possible application in enhanced oil recovery. Int Biodeterior Biodegrad 81:141-146

Al-Sulaimani H et al (2011) Microbial biotechnology for enhancing oil recovery: current developments and future prospects. Biotechnol Bioinf Bioeng 1(2): 147-158

Al-Sulaimani H et al (2012) Residual-oil recovery through injection of biosurfactant, chemical surfactant, and mixtures of both under reservoir temperatures: induced-wettability and interfacial-tension effects. SPE Reserv Eval Eng 15(02):210-217

Al-Wahaibi Y et al (2014) Biosurfactant production by Bacillus subtilis B30 and its application in enhancing oil recovery. Colloids Surf, B 114:324-333

Anderson W (1986) Wettability literature survey-part 2: wettability measurement. J Petrol Technol 38(11):1246-1262

Armstrong RT, Wildenschild D (2012a) Investigating the pore-scale mechanisms of microbial enhanced oil recovery. J Pet Sci Technol 94:155-164

Armstrong RT, Wildenschild D (2012b) Microbial enhanced oil recovery in fractional-wet systems: a pore-scale investigation. Transport Porous Med 92(3):819-835

Austad T (2013) Water-based EOR in carbonates and sandstones: new chemical understanding of the eor potential using smart water. Enhanced Oil Recovery Field Case Studies, chap 13, p 302

Box GE, Wilson K (1951) On the experimental attainment of optimum conditions. J R Stat Soc: Ser B (Methodol) 13(1):1-45

Burgos-Díaz C et al (2011) Isolation and partial characterization of a biosurfactant mixture produced by Sphingobacterium sp. isolated from soil. J Colloid Interface Sci 361(1):195-204

Bushnell L, Haas H (1941) The utilization of certain hydrocarbons by microorganisms. J Bacteriol 41(5):653

Coates J (2000) Interpretation of infrared spectra, a practical approach. Encycl Anal Chem 
Darvishi P, Ayatollahi S, Mowla D, Niazi A (2011) Biosurfactant production under extreme environmental conditions by an efficient microbial consortium, ERCPPI-2. Colloids Surf B. Biointerfaces 84(2):292-300

de Faria AF et al (2011) Production and structural characterization of surfactin (C 14/Leu 7) produced by Bacillus subtilis isolate LSFM-05 grown on raw glycerol from the biodiesel industry. Process Biochem 46(10):1951-1957

Dorozhkin SV (2009) Calcium orthophosphates in nature, biology and medicine. Materials 2(2):399-498

Fisher J, Boles J (1990) Water-rock interaction in Tertiary sandstones, San Joaquin basin, California, USA: diagenetic controls on water composition. Chem Geol 82:83-101

Gudina EJ et al (2013) Biosurfactant-producing and oil-degrading Bacillus subtilis strains enhance oil recovery in laboratory sandpack columns. J Hazard Mater 261:106-113

Gudiña EJ, Pereira JF, Rodrigues LR, Coutinho JA, Teixeira JA (2012) Isolation and study of microorganisms from oil samples for application in microbial enhanced oil recovery. Int Biodeterior Biodegrad 68:56-64

Henkel M et al (2012) Rhamnolipids as biosurfactants from renewable resources: concepts for next-generation rhamnolipid production. Process Biochem 47(8):1207-1219

Illias R, Ooi S, Idris A, Rahman W (1999) Production of biosurfactant and biopolymer from Malaysian oil fields isolated microorganisms. In: SPE Asia Pacific improved oil recovery conference. Society of Petroleum Engineers

Jacques P et al (1999) Optimization of biosurfactant lipopeptide production from Bacillus subtilis S499 by Plackett-Burman design. In: Twentieth symposium on biotechnology for fuels and chemicals, Springer, Berlin, pp 223-233

Javadi A et al (2013) Characterization methods for liquid interfacial layers. Eur Phys J Spec Top 222(1):7-29

Joshi S, Bharucha C, Desai AJ (2008a) Production of biosurfactant and antifungal compound by fermented food isolate Bacillus subtilis 20B. Bioresour Technol 99(11):4603-4608

Joshi S, Yadav S, Desai AJ (2008b) Application of response-surface methodology to evaluate the optimum medium components for the enhanced production of lichenysin by Bacillus licheniformis R2. Biochem Eng J 41(2):122-127

Karimi M, Mahmoodi M, Niazi A, Al-Wahaibi Y, Ayatollahi S (2012) Investigating wettability alteration during MEOR process, a micro/macro scale analysis. Colloids Surf B: Biointerfaces 95:129-136

Khuri A, Cornell J (1987) Response surfaces: designs and analyses. Marce 1 Dekker. Inc., New York

Krüger M et al (2016) Sampling for MEOR: comparison of surface and subsurface sampling and its impact on field applications. J Petrol Sci Eng 146:1192-1201

Lazar I, Petrisor I, Yen T (2007) Microbial enhanced oil recovery (MEOR). Pet Sci Technol 25(11):1353-1366

Le NYT, Pham DK, Le KH, Nguyen PT (2011) Design and screening of synergistic blends of $\mathrm{SiO} 2$ nanoparticles and surfactants for enhanced oil recovery in high-temperature reservoirs. Adv Nat Sci: Nanosci Nanotechnol 2(3):035013

Loglio G et al (2001) Drop and bubble shape analysis as a tool for dilational rheological studies of interfacial layers. Stud Interface Sci 11:439-483

Lotfabad TB et al (2009) An efficient biosurfactant-producing bacterium Pseudomonas aeruginosa MR01, isolated from oil excavation areas in south of Iran. Colloids Surf B. Biointerfaces 69(2):183-193

Mahani H, Berg S, Ilic D, Bartels W-B, Joekar-Niasar V (2015) Kinetics of low-salinity-flooding effect. SPE J 20(01):8-20

Marchant R, Banat IM (2012) Biosurfactants: a sustainable replacement for chemical surfactants? Biotechnol Lett 34(9):1597-1605
Mooney RW, Meisenhelter G (1960) Solubility of CaHPO4 at $90{ }^{\circ} \mathrm{C}$. J Chem Eng Data 5(3):373-374

Mukerjee P, Mysels KJ (1971) Critical micelle concentrations of aqueous surfactant systems. DTIC Document

Mulligan CN (2005) Environmental applications for biosurfactants. Environ Pollut 133(2):183-198

Najafi A et al (2015) Comparison and modification of models in production of biosurfactant for Paenibacillus alvei and Bacillus mycoides and its effect on MEOR efficiency. J Petrol Sci Eng 128:177-183

Nielsen SM (2010) Microbial enhanced oil recovery-advanced reservoir simulation. Department of Chemical and Biochemical Engineering

Nitschke M, Pastore GM (2004) Biosurfactant production by Bacillus subtilis using cassava-processing effluent. Appl Biochem Biotechnol 112(3):163-172

Owens W, Archer D (1971) The effect of rock wettability on oilwater relative permeability relationships. J Petrol Technol 23(07):873-878

Peng F, Liu Z, Wang L, Shao Z (2007) An oil-degrading bacterium: rhodococcus erythropolis strain $3 \mathrm{C}-9$ and its biosurfactants. J Appl Microbiol 102(6):1603-1611

Pereira JF et al (2013) Optimization and characterization of biosurfactant production by Bacillus subtilis isolates towards microbial enhanced oil recovery applications. Fuel 111:259-268

Rabiei A, Sharifinik M, Niazi A, Hashemi A, Ayatollahi S (2013) Core flooding tests to investigate the effects of IFT reduction and wettability alteration on oil recovery during MEOR process in an Iranian oil reservoir. Appl Microbiol Biotechnol 97(13):5979-5991

Rashid S, Mousapour MS, Ayatollahi S, Vossoughi M, Beigy AH (2015) Wettability alteration in carbonates during "Smart Waterflood": underlying mechanisms and the effect of individual ions. Colloids Surf Physicochem Eng Aspects 487:142-153

Reis R, Pacheco G, Pereira A, Freire D (2013) Biosurfactants: production and applications. InTech, New York

Roldán-Carrillo T et al (2011) Evaluation of the effect of nutrient ratios on biosurfactant production by Serratia marcescens using a BoxBehnken design. Colloids Surf B. Biointerfaces 86(2):384-389

Sarafzadeh P, Hezave AZ, Ravanbakhsh M, Niazi A, Ayatollahi S (2013) Enterobacter cloacae as biosurfactant producing bacterium: differentiating its effects on interfacial tension and wettability alteration mechanisms for oil recovery during MEOR process. Colloids Surf B Biointerfaces 105:223-229

Sen R (1997) Response surface optimization of the critical media components for the production of surfactin. J Chem Technol Biotechnol 68(3):263-270

Shaw JC, Bramhill B, Wardlaw N, Costerton J (1985) Bacterial fouling in a model core system. Appl Environ Microbiol 49(3):693-701

Sivakumar N, Al-Bahry S, Al-Battashi HS (2013) Screening of biopolymer producing bacteria isolated from some brassica plants. APCBEE Proced 5:333-338

Souayeh M et al (2014) Optimization of a low-concentration bacillus subtilis strain biosurfactant toward microbial enhanced Oil recovery. Energy Fuels 28(9):5606-5611

Soudmand-asli A, Ayatollahi SS, Mohabatkar H, Zareie M, Shariatpanahi SF (2007) The in situ microbial enhanced oil recovery in fractured porous media. J Pet Sci Technol 58(1):161-172

Tavassoli T, Mousavi S, Shojaosadati S, Salehizadeh H (2012) Asphaltene biodegradation using microorganisms isolated from oil samples. Fuel 93:142-148

Thaniyavarn J et al (2003) Production and characterization of biosurfactants from Bacillus licheniformis F2. 2. Biosci Biotechnol Biochem 67(6):1239-1244 
Thimon L, Peypoux F, Michel G (1992) Interactions of surfactin, a biosurfactant from Bacillus subtilis, with inorganic cations. Biotechnol Lett 14(8):713-718

Wei Y-H, Lai C-C, Chang J-S (2007) Using Taguchi experimental design methods to optimize trace element composition for enhanced surfactin production by Bacillus subtilis ATCC 21332. Process Biochem 42(1):40-45

Weisburg WG, Barns SM, Pelletier DA, Lane DJ (1991) 16S ribosomal DNA amplification for phylogenetic study. J Bacteriol 173(2):697-703
Youssef NH et al (2004) Comparison of methods to detect biosurfactant production by diverse microorganisms. J Microbiol Methods 56(3):339-347

Zhao F et al (2017) Biosurfactant production under diverse conditions by two kinds of biosurfactant-producing bacteria for microbial enhanced oil recovery. J Petrol Sci Eng 157:124-130

Publisher's Note Springer Nature remains neutral with regard to jurisdictional claims in published maps and institutional affiliations. 